\title{
ASPECTOS CONCEPTUALES Y TIPOLÓGICOS DE LA REGULACIÓN DE LAS SOCIEDADES DE CAPITAL EN EL DERECHO ESPAÑOL ${ }^{*}$
}

\author{
BASIC AND TYPOLOGICAL FEATURES OF COMPANIES’ REGULATION \\ IN SPANISH LAW
}

\author{
José Miguel Embid Irujo ${ }^{* *}$
}

\begin{abstract}
RESUMEN: Desde su entrada en vigor en septiembre de 2010, la Ley de sociedades de capital constituye el elemento normativo fundamental de esta categoría societaria en el ordenamiento español. En el presente trabajo se describen sus caracteres fundamentales, su sistema de fuentes, con especial referencia al Derecho de la Unión europea, así como el relieve de la autonomía de la voluntad, por vía de las cláusulas estatutarias o de los pactos parasociales, para la configuración efectiva de cada sociedad. El estudio concluye con la presentación de los tipos regulados en la ley (sociedad anónima, sociedad de responsabilidad limitada y sociedad comanditaria por acciones), y con alguna referencia somera a otras figuras, autónomas o derivadas de los tipos básicos, igualmente reguladas en dicho texto legal, de entre las que destaca la sociedad anónima europea.
\end{abstract}

Palabras clave: Derecho español de sociedades, Ley de sociedades de capital, autonomía de la voluntad, tipología societaria.

\begin{abstract}
Since its entry into force in September 2010, the Corporate Enterprises Act constitutes the fundamental normative element of this company category in the Spanish legal system. The present work describes its fundamental character, its system of sources, with special reference to the European Union Law, as well as the highlighting of the free will of the parties, by way of bylaw clauses or shareholders agreements, for the effective configuration of each company. The study concludes with the presentation of types of companies recognized by this Act (stock corporation, limited liability company and limited partnership), and with some superficial reference to other kinds, autonomous or derivatives of the basic types, also regulated in the legal text, among which the European company stands out.
\end{abstract}

Key words: Spanish Company Law, Corporate Enterprises Act, Free will of the parties, Company typology.

\footnotetext{
* El presente trabajo se inserta en el proyecto de investigación "Crisis económica y Derecho de sociedades" (DER 18660-2010), concedido por el Ministerio de Ciencia e Innovación de España, y del que es investigador principal el autor. A su vez, con ligeras modificaciones, constituye el capítulo introductorio de un amplio libro colectivo sobre el régimen jurídico de las sociedades de capital en el Derecho español, que verá la luz próximamente y del que son autores los miembros de Commenda, grupo de investigación en Derecho de sociedades (www.commenda.es). Agradezco a Jaime Alcalde Silva su cuidadosa revisión del texto.

** Catedrático de Derecho mercantil, Universidad de Valencia. Correo electrónico: jose.m.embid@uv.es
} 


\section{SENTIDO Y RAZÓN DEL DERECHO DE SOCIEDADES DE CAPITAL EN EL ORDENAMIENTO ESPAÑOL}

\subsection{El Derecho de sociedades de capital como Categoría jurídica y su RECEPCiÓN LIMITADA EN LA LEY DE SOCIEDADES DE CAPITAL}

Hasta la entrada en vigor del Real Decreto Legislativo 1/2010, de 2 de julio, por el que se aprobó el texto refundido de la Ley de sociedades de capital (en adelante, LSC) en el ordenamiento jurídico español, la fórmula "sociedades de capital" (o su equivalente "sociedades capitalistas") era objeto de uso, casi exclusivamente, por los juristas dedicados al estudio y a la aplicación del Derecho de sociedades. A la hora de articular el amplio contenido del Derecho de sociedades mercantiles, dicha fórmula concurría con la expresión "sociedades de personas" (o su equivalente "sociedades personalistas"), dando lugar, así, a una división fundamental de esta materia jurídica en dos grandes categorías conceptuales, diferenciadas por el distinto relieve que, en cada una de ellas, debía atribuirse a la persona de los socios para la existencia, configuración, régimen jurídico y responsabilidad de la concreta sociedad $^{1}$. Si ese relieve podía considerarse máximo dentro de las sociedades de personas, como la colectiva o la comanditaria simple, su trascendencia, en cambio, para las sociedades de capital (anónima, limitada y comanditaria por acciones) resultaba sensiblemente inferior, sin perjuicio, no obstante, de algunas diferencias significativas entre los distintos tipos ${ }^{2}$.

Aunque, por lo expuesto, la expresión misma "sociedades de capital" era obvia para los muchos interesados en el Derecho de sociedades mercantiles, no estará de más recordar, a la hora de fijar su significado jurídico básico, que los elementos mínimos comunes a los diversos tipos integrantes de dicha categoría pueden resumirse, fundamentalmente, en los dos siguientes: (i) la necesaria existencia de un capital social integrado por las aportaciones de los socios, dividido, bien en acciones (sociedad anónima y sociedad comanditaria por acciones), bien en participaciones (sociedad de responsabilidad limitada), y (ii) la irresponsabilidad de los socios por las deudas sociales, sin perjuicio del efecto contrario para aquellos accionistas de la sociedad comanditaria por acciones que sean, a la vez, sus administradores, a los que se aplicará la responsabilidad característica de los socios colectivos ${ }^{3}$.

La referencia a las "sociedades de capital" ha sido, desde luego, una constante entre los expertos en el estudio del Derecho de sociedades, si bien su empleo se generaliza y se extiende más allá del círculo de los juristas a partir, sobre todo, de la gran reforma societaria llevada a cabo en el siglo pasado con motivo del ingreso de España en la Unión Europea ( 1 de enero de 1986). Como es bien sabido, el cambio legislativo afectó, esencialmente, a las diversas figuras que se insertan en la categoría "sociedades de capital", en particular a la anónima y, con posterioridad, a la sociedad de responsabilidad limitada. La trascendencia de las modificaciones normativas dio lugar a un gran incremento de publicaciones de todo

\footnotetext{
1 Por todos, véase Girón (1976) pp. 138, 176, 276 y 306, entre otras muchas referencias.

2 Cfr. Sánchez, SÁnchez-Calero (2011) pp. 318-320. Véase asimismo, entre la manualística contemporánea, Broseta/Martínez (2011) pp. 279 ss.

3 En la misma línea, Vaquerizo (2011) p. 182.
} 
signo sobre las cuestiones propias de dicha categoría, coincidiendo, al mismo tiempo, con una distinta implantación de sus tipos en la realidad empresarial. Frente al tradicional predominio de la anónima, la sociedad de responsabilidad limitada va a iniciar un progresivo ascenso que la convertirá en el tipo preferido por los operadores económicos en España, circunstancia que, como es bien sabido, se mantiene en nuestros días.

En cualquier caso, debe advertirse que, a pesar del tiempo transcurrido, no se ha conseguido construir un perfil nítido de las sociedades de capital como categoría jurídica ${ }^{4}$. Aunque son conocidos los elementos comunes a todas ellas, empezando precisamente por el capital social, la dificultad de distinguir nítidamente entre la anónima y la limitada, al menos en lo que se refiere a sus características esenciales, tradicional en el Derecho español, ha ensombrecido la cuestión y ha dificultado también el establecimiento de un régimen jurídico general aplicable a todas los tipos capitalistas. La aprobación de la LSC, por su parte, no ha conseguido llenar ese importante vacío, a pesar de que existen en ella algunos aspectos provistos de un tratamiento común, eso sí, con carácter limitado. Con todo, el hecho de que la mencionada ley no contenga, en toda su extensión, el necesario régimen común a las sociedades de capital no permite criticar el proceder legislativo. Como es notorio, no era ese el objetivo básico de la LSC, teniendo en cuenta su carácter de texto refundido; en tal sentido, la finalidad perseguida por el legislador consistía meramente en regularizar, armonizar y aclarar las normas refundidas ${ }^{5}$, de acuerdo con el mandato contenido en la disposición final séptima de la Ley 3/2009, de 3 de abril, de modificaciones estructurales de las sociedades mercantiles (en adelante, LMESM). No puede ocultarse, sin embargo, que los cambios llevados a cabo en las normas refundidas han ido más allá, en varios casos, de lo que cabía presumir con arreglo a la finalidad pretendida; se comprende, así, que estos ultra vires de la LSC, como se ha dicho ${ }^{6}$, hayan dado pie, junto con otras circunstancias, a la presentación de diversos recursos todavía no resueltos en el momento de escribir estas líneas. Todo ello, claro está, sin perjuicio de las dificultades e inconvenientes que la elaboración de una ley tan compleja como la LSC ha traído consigo, además de los errores, muchos de ellos relevantes, que contenía el texto originario ${ }^{7}$.

\subsection{LA SINGULARIDAD DE LA LSC}

Por otro lado, no debe ignorarse la singularidad de la ley que nos ocupa como pieza normativa del ordenamiento jurídico español. Frente a lo que suele ser común, sobre todo en textos legales de tanto relieve, el legislador no ha concebido la LSC como una regulación estable o fija o, si se quiere, con propósito duradero, en la medida en que estos calificativos pueden aplicarse a una norma jurídica. Al contrario, según lo que se deduce de su exposición de motivos, constituye dicha ley una regulación claudicante, o, dicho con otras pala-

\footnotetext{
4 Últimamente, Alonso, et al. (2011).

5 En lo que ahora interesa, se trataba de la Ley de sociedades anónimas y la Ley de sociedades de responsabilidad limitada, que han sido derogadas por la LSC, sin perjuicio de algunas reglas sobre las sociedades cotizadas contenidas en la Ley del Mercado de Valores (en adelante, LMV), cuya vigencia, al margen de ellas, se mantiene en la actualidad.

6 Véase, en tal sentido, MuÑoz (2011).

7 Sobre estas circunstancias, QuiJano (2011).
} 
bras, una suerte de "estación intermedia" entre la situación previa del Derecho español de sociedades de capital, caracterizado por la pluralidad y dispersión de fuentes, así como por diversas incongruencias y contradicciones entre sus distintas piezas, y el propósito de conseguir un Código general de sociedades mercantiles. De ahí viene la conocida y paradójica "voluntad de provisionalidad" de la LSC, abiertamente confesada en su exposición de motivos, que permite dudar, con fundamento, de si nos encontramos ante una ley necesaria.

Aunque responder a esta pregunta no revista hoy valor práctico alguno, cabe afirmar que las reformas principales que ha traído consigo la LSC podían haberse efectuado sin alterar de forma tan drástica el statu quo legislativo anterior. Con independencia de sus indudables inconvenientes, tanto los operadores jurídicos como los económicos estaban familiarizados con la situación de especialidad legislativa previa y con la consiguiente regulación separada de los distintos tipos. Sustituir ese marco de referencia por otro concebido, a priori, como transitorio, no parece, en principio, la mejor política legislativa, si se tiene en cuenta, sobre todo, que las líneas maestras del Derecho de sociedades de capital no han sufrido (ni debían sufrir) modificaciones relevantes con la LSC. Es posible, además, que la provisionalidad de esta última deje de serlo como consecuencia de las múltiples dificultades que circundan la elaboración de un Código de sociedades mercantiles en España o que, al contrario, mantenga la LSC su vigencia más allá de lo razonable, a la vista de lo problemático que resulta hoy cualquier proyecto legislativo, de alcance codificador o no, en Derecho de sociedades por las derivaciones de la crisis económica. En este contexto, conviene no olvidar el fracaso de la Propuesta de Código de sociedades mercantiles, presentada por el Ministerio de Justicia en 2002, así como las circunstancias que la hicieron posible. Del mismo modo, ha de seguirse con atención el discurrir de los trabajos que sobre el mencionado Código se llevan a cabo en la Sección de Derecho Mercantil de la Comisión General de Codificación, que, por desgracia, carecen de la debida transparencia en asunto tan relevante.

\section{LAS FUENTES DEL DERECHO ESPAÑOL DE SOCIEDADES DE CAPITAL}

\subsection{LAS FUENTES LEGISLATIVAS INTERNAS}

La continua referencia que se viene haciendo a la LSC, como expresión de la regulación española en la materia, podría sugerir la idea de que dicho texto es el único relevante a la hora de establecer el régimen jurídico de las distintas figuras que integran la categoría "sociedades de capital"; dicho de otra manera, que la LSC es la única fuente normativa del Derecho español de sociedades de capital. Como punto de partida, esta afirmación es sustancialmente cierta, debido a la amplitud y minuciosidad de la regulación que, al respecto, se contiene en la LSC, cuyo artículo 3 viene a patrocinar, en forma un tanto indirecta, su carácter central en la ordenación jurídica de las sociedades de capital en España. No se trata, con todo, de una fuente única desde el punto de vista del ordenamiento español, ya que, como es evidente, debe contarse con lo dispuesto en el Reglamento del Registro Mercantil (en adelante, RRM), cuya adaptación a la disciplina de la LSC, todavía no aprobada, es cada vez más urgente. Y no deberían olvidarse, a pesar de su reducida trascendencia, las reglas generales que sobre el contrato de compañía se contienen en el Código de comercio, 
a la espera de que se pueda disponer en el futuro Código de sociedades mercantiles de un tratamiento común aplicable a todas las figuras que merezcan dicho calificativo.

A pesar del escaso tiempo transcurrido desde su entrada en vigor, la LSC ha sufrido cuatro modificaciones por parte del legislador español: dos de ellas pueden ser consideradas relevantes, en tanto que las restantes, sin perjuicio de su importancia, parecen tener un alcance más reducido ${ }^{8}$. La primera modificación relevante se produce merced al Real Decreto Ley 13/2010, de 3 de diciembre, de actuaciones en el ámbito fiscal, laboral y liberalizadoras para fomentar la inversión y la creación de empleo, que pretende agilizar, simplificar y abaratar determinados actos y circunstancias de la vida de las sociedades de capital. Así, se hace posible la constitución telemática de todas ellas, con matices que ahora no vienen al caso, y se introduce la posibilidad de publicar anuncios y convocatorias en la página web de la propia sociedad, eliminándose, de este modo, la tradicional difusión de los mismos en la prensa.

Más recientemente, encontramos una segunda reforma relevante de la LSC en la Ley 25/2011, de 1 de agosto, que, además de incorporar las normas contenidas en la Directiva 2007/36, del Parlamento europeo y del Consejo, de 11 de julio, sobre el ejercicio de determinados derechos de los accionistas de las sociedades cotizadas, ha supuesto la modificación de diversos preceptos ajenos al régimen de estas últimas. Algunos de esos cambios se conectan a materias ya contempladas en el Real Decreto-Ley 13/2010, como se aprecia en el artículo 11 bis (sede electrónica), en tanto que otros afectan al estatuto de los socios, en punto al régimen de separación o exclusión, con normas tan singulares como la contenida, por ejemplo, en el artículo 349 bis, que contempla un supuesto de derecho de separación derivado de la falta de distribución de dividendos?

De menor extensión, en apariencia, pero vinculada a aspectos tan significativos como los relativos al artículo 11 bis, hoy rotulado "página web de la sociedad", la convocatoria de la Junta y, mediante disposiciones adicionales, la reinstauración de la licitud del blindaje societario para las sociedades cotizadas, es la última reforma de la LSC, llevada a cabo, inicialmente, por el Real Decreto-Ley 9/2012, de 16 de marzo, y definitivamente por la Ley $1 / 2012$, de 22 de junio, de simplificación de las obligaciones de información y documentación de fusiones y escisiones de sociedades de capital. En realidad, esta reforma se planteó, en un principio, como un cambio particular del régimen de las modificaciones estructurales, de acuerdo con las últimas directivas aprobadas por la Unión Europea en la materia. Se trataba en los textos comunitarios de simplificar y flexibilizar el tratamiento de estas relevantes alteraciones societarias, de modo que su tramitación fuera más sencilla. En la línea de lo descrito con anterioridad, el legislador español ha aprovechado la ocasión para introducir otros cambios, estos sí referidos de modo directo a la LSC, como son los relativos al régimen de la página web y, específicamente vinculado a esta cuestión, la convocatoria de la Junta gene-

8 Sobre estas reformas, véase, recientemente, Rodríguez, Farrando, GonZÁlez (2012).

9 Posibilidad esta que la reforma llevada a cabo por la Ley 1/2012, de 22 de junio, también analizada en el texto, ha dejado en suspenso por el plazo de dos años. No parece ser ajena a esta medida, sin duda excepcional, la situación de grave crisis por la que atraviesa la economía española y que ha aconsejado evitar la puesta en práctica de medidas, como la indicada, susceptibles de acarrear serios problemas para la continuidad de las empresas. 
ral. Por último, las disposiciones adicionales han dado pie a ulteriores reformas de la LSC y también de la LMV, a propósito, según se ha señalado, de un asunto tan relevante como la licitud de las cláusulas de blindaje en las sociedades cotizadas, ahora recuperadas, eso sí, en conexión directa con el régimen de las ofertas públicas de adquisición ${ }^{10}$.

Por último, se ha de mencionar la modificación de la LSC que ha traído consigo la Ley 2/2011, de 4 de marzo, de Economía Sostenible, que, sin ser la más reciente en el tiempo es, tal vez, la menos significativa en cuanto a su relieve. Dicha ley ha supuesto la alteración del artículo 497 LSC, en el sentido de hacer más transparente la estructura social de las sociedades cotizadas.

Estos continuos cambios en el contenido de la LSC, no siempre objeto de la debida meditación, confieren a dicha ley una censurable imagen de regulación inestable y carente de la debida fijeza ${ }^{11}$. No se trata, con todo, de la "provisionalidad" a la que alude su exposición de motivos, la cual, como sabemos, solo significa el anuncio, un tanto impreciso en sus detalles, de su futura sustitución por el Código de sociedades mercantiles. Nos encontramos, por tanto, ante una provisionalidad "añadida" que hace más inseguro el régimen jurídico de las sociedades de capital en el Derecho español. Con todo, la eventualidad de ulteriores reformas, así como la elaboración del mencionado Código, no privan a la LSC de su posición privilegiada como fuente esencial del Derecho español de sociedades de capital en el momento presente, lo que implica, como es evidente, la necesidad de su continuo análisis por parte de los numerosos interesados en la materia, que no son solo los juristas.

\subsection{LAS FUENTES LEGISLATIVAS EXTERNAS}

Al margen de las fuentes legislativas internas, a la hora de trazar el conjunto de fuentes reguladoras de las sociedades de capital en nuestro ordenamiento, hay que tener en cuenta la relevante contribución del Derecho de la Unión Europea. Como es bien sabido, una de las materias destacadas del ordenamiento jurídico europeo es, precisamente, el Derecho de sociedades mercantiles. Sobre dicho sector se han proyectado los esfuerzos de los organismos europeos competentes durante un periodo cercano al medio siglo, sufriendo los avatares de la propia construcción europea, así como la asunción de opciones diversas e,

\footnotetext{
10 A pesar de la amplia incidencia de la reforma en el Derecho de sociedades, en la denominación del Real Decreto-Ley 9/2012 y de la Ley 1/2012, de 22 de junio, se alude exclusivamente a las cuestiones propias de las modificaciones estructurales, prescindiendo de los demás aspectos de su contenido mencionados en el texto.

11 Obsérvese, por lo demás, que el instrumento normativo utilizado para dichas modificaciones ha sido en dos ocasiones el Decreto-Ley, figura normativa esta ajena, por lo común, al establecimiento y evolución del régimen jurídico de las sociedades, y no solo mercantiles, en el ordenamiento jurídico español. Si la urgencia del Real Decreto-Ley de 2010 parecía deberse a razones exclusivas de la crisis económica, a la que se pensaba combatir con unas medidas que, desde el punto de vista del Derecho de sociedades, podrían mejorar la competitividad de las empresas, en el caso del Real Decreto-Ley 9/2012 la razón, en apariencia, es mucho más pedestre, pues ahora se trata de evitar retrasos en la incorporación de directivas comunitarias que permitan a la Unión Europea sancionar (económicamente, claro está) a España. Con todo, ese hipotético retraso no se refería a la LSC, sino a la LMESM, cuya modificación ha sido de mucho mayor alcance, lo que no ha impedido, sin embargo, que el legislador haya considerado oportuno reformar aquella, sin que esa alteración normativa viniera condicionada o impuesta por la necesidad de adaptar el ordenamiento español al Derecho europeo de sociedades.
} 
incluso, contrapuestas en torno a los criterios de política jurídica aplicables a la regulación de las sociedades.

Sin perjuicio, entonces, de los cambios que la evolución del proceso ha traído consigo, puede afirmarse, a modo de síntesis, que han sido dos las finalidades fundamentales perseguidas por la Unión Europea a propósito del Derecho de sociedades: en primer lugar, la armonización de la normativa societaria de los Estados miembros, a través de la aprobación de las correspondientes directivas, y, en segundo lugar, la elaboración de un Derecho europeo de sociedades con carácter uniforme, a fin de hacer posible la creación de figuras societarias específicamente europeas, mediante la promulgación de los oportunos reglamentos. Durante un buen periodo de tiempo, ha sido la finalidad armonizadora la que ha prevalecido, reflejándose, sobre todo, en el régimen jurídico de la sociedad anónima y, en menor medida, en las restantes sociedades de capital. Solo en nuestro siglo, ha alcanzado cierta madurez el propósito de crear figuras societarias de Derecho europeo, algunas de ellas insertas también en el terreno que nos ocupa, como la sociedad anónima europea, sin que haya llegado a materializarse la elaboración del reglamento de la sociedad privada europea, como remedo, a escala continental, de la sociedad de responsabilidad limitada ${ }^{12}$.

Una buena parte del acervo comunitario sobre las sociedades de capital había sido ya incorporado al ordenamiento español con motivo de la integración de España en la Unión Europea. En ese momento se dio cauce a la transposición en bloque de todas las directivas vigentes, lo que supuso, tal vez, la reforma societaria más importante en el Derecho español desde la promulgación de las leyes de anónimas y de limitadas a mediados del siglo XX. En los más de veinticinco años transcurridos desde entonces, muchas han sido las normas del Derecho europeo de sociedades implementadas por el legislador, directivas, en su mayor parte, y, en menor medida, reglamentos, manteniéndose la sociedad anónima como referencia fundamental de la legislación europea, sin perjuicio del tratamiento, sensiblemente menor, de las restantes sociedades de capital.

Puede decirse, por ello, que el Derecho europeo constituye una fuente relevante del Derecho español de sociedades de capital, con mayor intensidad y efectividad de lo que sucede en otros sectores del Derecho mercantil, quizá la rama del ordenamiento jurídico más afectada por la integración jurídica europea. Los principios de primacía y de efecto útil tienen en nuestro campo, como no podía ser menos, una estricta aplicación, determinando, en consecuencia, la subordinación de las fuentes nacionales a lo que resulte de las normas aprobadas por los órganos competentes de la Unión Europea. En ese sentido, la LSC es fiel reflejo de esa influencia, ya que su texto no hace sino reproducir las normas de las leyes refundidas que habían transpuesto en su momento los preceptos pertinentes de las directivas y reglamentos europeos.

12 En España no existe una obra monográfica que dé cuenta de manera completa del Derecho europeo de sociedades, a diferencia de lo que ocurre en otros ordenamientos. Al respecto, puede verse, por muchos, GRUNDMANN (2011). Conviene observar, no obstante, que el Derecho europeo de sociedades no es un todo monolítico y que su dilatada evolución muestra la influencia de criterios no precisamente homogéneos; así se refleja en los últimos años con la atención al gobierno corporativo y a la simplificación del material normativo. Sobre esto, por muchos, véase Hierro (2010). 
Los últimos ejemplos de vinculación permanente al Derecho europeo, a la vez, servidumbre y grandeza de la integración en una organización supranacional como la Unión Europea, lo constituyen, de un lado, la Ley 25/2011, de 1 de agosto, de reforma de la Ley de sociedades de capital y de incorporación de la Directiva 2007/36, del Parlamento europeo y del Consejo, de 11 de julio, sobre el ejercicio de determinados derechos de los accionistas de las sociedades cotizadas, y, de otro, el Real Decreto-Ley 9/2012, de 16 de marzo, junto con la Ley 1/2012, de 22 de junio, que ha supuesto la incorporación de la Directiva 2009/109/CE del Parlamento europeo y del Consejo, de 16 de septiembre de 2009. Conviene observar, no obstante, que dichas normas no se han limitado a servir de cauce, exclusivamente, a la transposición del Derecho europeo de sociedades, sino que han supuesto también una reforma del ordenamiento español por causas puramente internas, con alcance, eso sí, diverso en cada caso. Se sigue, así, una tendencia iniciada ya con la transposición de las Directivas societarias vigentes en el momento de ingreso de España en la Unión Europea, y que se ha repetido en numerosas ocasiones desde entonces, convirtiéndose de este modo en un proceder característico del legislador con motivo de la reforma continua del Derecho español de sociedades.

\section{La autonomía de la voluntad en el Derecho de Sociedades de capital}

\section{A) El relieve de los estatutos}

Aludir a la autonomía de la voluntad a propósito de las fuentes del Derecho de las sociedades de capital ${ }^{13}$ no implica atribuirle un rango que, en sustancia, no le corresponde dentro de un sistema jurídico, como el español, que ha hecho, y sigue haciendo, en buena medida, de la ley, el principal instrumento de ordenación normativa de la vida humana en sociedad. Al fin y al cabo, el tratamiento que de dicho principio se hace en el artículo 28 LSC restringe su juego, como no podía ser de otro modo, a la escritura y los estatutos de la concreta sociedad en la que se aplica ${ }^{14}$. Son, sin duda, los estatutos el vehículo teóricamente privilegiado para la puesta en práctica de la autonomía de la voluntad de los socios, lo que explica la atención que reciben en la LSC sus aspectos esenciales, desde la determinación de su contenido inicial hasta su modificación, materia sometida, como es sabido, a un minucioso procedimiento de desarrollo. Ello se debe a que, sin perjuicio de su origen negocial, renovado mediante acuerdo mayoritario con motivo de su modificación, hay en los estatutos una dimensión organizativa que refleja debidamente la vertiente institucional de toda sociedad y, en particular, de las de naturaleza capitalista ${ }^{15}$. Se entiende, por ello,

\footnotetext{
13 No nos referiremos en este capítulo a la Jurisprudencia como fuente del Derecho y, más en particular, del régimen propio de las sociedades de capital. Se trata de una cuestión cuyo carácter polémico parece más bien del pasado, sin perjuicio de que, respecto de nuestro tema, adquiera un relieve extraordinario gracias, desde luego, a los numerosos fallos del Tribunal Supremo sobre sus distintas materias (aunque, como es lógico, ninguno de ellos se funde, hasta el momento, en los preceptos de la LSC como ratio decidendi), pero también a las continuas resoluciones de la Dirección General de los Registros y del Notariado (en adelante, DGNR) que se ocupan de materias vinculadas con dicha norma con cercanía extraordinaria a su entrada en vigor.

14 Véase Duque (1991).

15 En Girón (1976, pp. 276-279) puede verse una sucinta y acertada caracterización de los estatutos en el ámbito de dichas sociedades.
} 
que la configuración concreta de las cláusulas estatutarias es una tarea básica y, a la vez, permanente mediante la cual podrán los socios ajustar la organización y el funcionamiento de la sociedad a las variables circunstancias, tanto externas como internas, susceptibles de plantearse a lo largo de su existencia ${ }^{16}$.

\section{B) La utilización habitual de formularios de estatutos redactados previamente}

(a) Premisa

No parece, con todo, que se haga uso efectivo de la libertad de configuración estatutaria reconocida por la LSC en la práctica societaria. Y no, desde luego, porque sean particularmente estrictos los límites señalados en ella a la autonomía de la voluntad, de modo que su vigencia suponga "ahogar" su ejercicio. Aun siendo legítimo sostener esta opinión, ampliamente difundida entre los partidarios del análisis económico del Derecho, tan difundido en los últimos años, parece que las causas del reducido uso de la libertad contractual en el tema que nos ocupa se explican, más bien, por otras circunstancias. Algunas de ellas, quizá las menos, se deducen de la, en ocasiones, interpretación reglamentista que, desde el Registro mercantil, se lleva a cabo de la normativa vigente en la materia. Las más se vinculan, en cambio, a la frecuencia con la que se recurre, desde hace tiempo, al uso de formularios redactados previamente, que convierten a los estatutos en documentos casi irrelevantes a la hora de conocer la concreta ordenación de una determinada sociedad. No se trata, por lo demás, de una tendencia exclusiva de la realidad jurídica española; repetidamente se ha advertido en la doctrina europea la frecuencia con la que se recurre a expedientes similares en la práctica societaria de muchos países.

(b) La incidencia de las nuevas tecnologías

A la intensificación de este planteamiento ha venido a contribuir, en fechas recientes, el criterio, comúnmente aceptado, de simplificar los trámites fundacionales de las sociedades de capitales (o, al menos, de algunos de sus tipos característicos) a fin de acortar, mediante el empleo de las nuevas tecnologías, el tiempo requerido para su efectiva constitución. Se ve en esta orientación, progresivamente aceptada en el Derecho comparado, un poderoso instrumento para mejorar la competitividad de las empresas, facilitando su inserción inmediata en el mercado y su adaptación a sus cambiantes requerimientos. Es oportuno señalar, en este punto, el carácter pionero del ordenamiento español, merced a la creación de la sociedad limitada nueva empresa, como modalidad de la sociedad de responsabilidad limitada, en la Ley 7/2003, de 1 de abril, actualmente regulada, sin alteraciones relevantes, en el título XII (artículos 434-454) de la LSC. En el contexto de dicha figura, carente de efectiva significación en la práctica empresarial española frente a las optimistas previsiones iniciales del legislador, la utilización de formularios de estatutos previamente redactados era un requisito sine qua non para lograr la ventaja competitiva inherente a su

\footnotetext{
16 Aun no siendo parte esencial del presente trabajo, parece necesario destacar la importancia, y la frecuencia, que ha adquirido en los últimos años la cláusula estatutaria de sumisión a arbitraje de los conflictos societarios, sobre todo a partir de la entrada en vigor de la nueva Ley de Arbitraje, de 20 de mayo de 2011, susceptible de extenderse, por lo demás, a todos los tipos y variedades de sociedades de capital.
} 
creación y que consistía en hacer posible su constitución efectiva en un plazo no superior a cuarenta y ocho horas. Es evidente que la celeridad supone reducir, de manera inevitable, el juego efectivo de la autonomía de la voluntad en la fase constitutiva de la sociedad, convirtiendo a las sociedades inscritas en el Registro mercantil mediante tal procedimiento en entidades "clónicas", sin más diferencia que su denominación, domicilio y, en su caso, cifra de capital.

La doctrina censuró, de manera prácticamente unánime, la restricción de la autonomía de la voluntad que terminaba suponiendo para la configuración estatutaria de la sociedad limitada nueva empresa la utilización de procedimientos telemáticos en su constitución. Pero, del mismo modo, se criticó con intensidad el hecho de que le legislador reservara el uso de las nuevas tecnologías a una modalidad societaria de nuevo cuño, marginando a los tipos generales existentes en el Derecho español, algunos de los cuales, como la sociedad limitada "general", habían demostrado cumplidamente su utilidad al servicio de proyectos empresariales equivalentes a los que se intentaba promover mediante la nueva figura ${ }^{17}$. Esta injustificada asimetría se ha salvado en fecha todavía reciente gracias a lo dispuesto en el Real Decreto Ley 13/2010, de 3 de diciembre, el cual, entre otros aspectos, ha venido a generalizar el procedimiento de constitución mediante medios telemáticos a todas las sociedades de capital. La finalidad de estimular, una vez más, la competitividad de las empresas, viene ahora reforzada con el objetivo de contribuir a la superación de la crisis económica, circunstancia esta que justificó, con escaso fundamento, la modificación de la LSC hecha a través de la mencionada norma. Con todo, la experiencia acumulada desde su entrada en vigor permite acreditar el empleo constante de las nuevas tecnologías con motivo de la constitución de sociedades de capital, y no solo, a nuestro juicio, por la reducción de aranceles de notarios y registradores impuesta por el Real Decreto Ley 13/2010, de 3 de diciembre. De ello es buena prueba la presencia habitual en las resoluciones de la DGRN de cuestiones relativas a estos aspectos, en particular los correspondientes a la llamada "constitución exprés", que permite reducir a un día el tiempo necesario para la constitución efectiva de una sociedad de capital ${ }^{18}$.

(c) El significado residual de los estatutos y el auge de los pactos parasociales

Como en el caso de la sociedad limitada nueva empresa, la aceleración del procedimiento de fundación de las sociedades de capital trae consigo, por su propia naturaleza, el empleo de formularios de estatutos redactados con carácter previo, lo que termina reduciendo sensiblemente el juego de la libertad contractual en dicha fase. Se trata, con toda seguridad, de un efecto inevitable, cuya progresiva generalización en la práctica societaria no parece haber suscitado especiales reticencias entre los operadores económicos. La cuestión resulta sorprendente, sobre todo si se tiene en cuenta el predominio en los últimos años de ciertas corrientes de pensamiento, como el análisis económico del Derecho, que han hecho

\footnotetext{
17 Por muchos, Embid (2003).

18 Se trata, sobre todo, de temas vinculados con cuestiones fiscales, como, por ejemplo, la posibilidad de inscribir las sociedades constituidas por procedimientos telemáticos sin necesidad de previa liquidación fiscal, por estar exentas. Entre las resoluciones más recientes, véase las de 29 de octubre de 2011, 16 de noviembre de 2011 y 26 de enero de 2012.
} 
de la autorregulación el instrumento idóneo y prácticamente exclusivo para ordenar las relaciones jurídicas en el ámbito de las sociedades mercantiles ${ }^{19}$. La inicial perplejidad que se suscita, no obstante, puede desvanecerse si se atiende a dos circunstancias, de diverso orden, que parecen estar detrás del fenómeno que ahora nos ocupa.

De un lado, y aunque faltan estudios empíricos para sostenerlo, parece que la constitución telemática de sociedades se aplica de manera predominante en el ámbito de las empresas de menor dimensión e, incluso, en el ámbito, más amplio numéricamente, pero de reducida trascendencia económica, de los emprendedores, categoría no bien perfilada y cuyo adecuado tratamiento quizá debiera merecer algunas reformas sustanciales en el Derecho mercantil, entre otros sectores jurídicos ${ }^{20}$. Este dato de la realidad permite entender que el "traje" de sociedad mercantil de capital (sobre todo, de sociedad de responsabilidad limitada) resulta quizá desproporcionado, al menos en su visión clásica, para un gran número de empresas, que se limitan a asumirlo como una mera superestructura externa, sin especiales repercusiones materiales en su funcionamiento cotidiano. Pero, al mismo tiempo, el ejercicio de la actividad de empresa bajo forma de sociedad atribuye a estos operadores económicos de reducida importancia algunas ventajas significativas; cabe citar entre ellas la atribución inmediata de personalidad jurídica, la estricta separación entre patrimonio social y patrimonio de los socios, frente al modelo de las sociedades de personas, y last but not least la posibilidad de obtener un tratamiento tributario más beneficioso que el correspondiente al empresario individual.

De otro lado, la relativa complejidad del funcionamiento de la sociedad mercantil como persona jurídica, así como - por qué no decirlo- el coste económico de los diversos trámites y actuaciones establecidos en la LSC, a pesar de las medidas de simplificación y flexibilización adoptadas en los últimos años, constituyen un elemento que desincentiva el

$19 \mathrm{Al}$ respecto, Embid (2009).

20 En esta línea se insertan algunos de los acuerdos adoptados por el Consejo de Ministros del Gobierno español a finales del mes de septiembre de 2012. Así, en la referencia divulgada a los medios de comunicación, se indica que en el semestre siguiente se aprobará por el propio Gobierno un plan de emprendedores que favorezca la creación, desarrollo y expansión de las pequeñas y medianas empresas españolas. De acuerdo con este objetivo, se creará la figura del emprendedor de responsabilidad limitada, se facilitará la segunda oportunidad en la creación de nuevos negocios y se impulsarán nuevas formas de financiación alternativa a la bancaria. A la espera, entonces, de la concreción de este programa, parece evidente que las futuras medidas que adopte el Gobierno repercutirán en el régimen jurídico de las estructuras organizativas utilizadas por los operadores económicos, considerando, desde luego, entre ellas a las sociedades mercantiles y, en particular, a las de capital. Por otro lado, la idea de crear la figura del "emprendedor de responsabilidad limitada" parece evocar no tanto un nuevo tipo de sociedad o, en su caso, una concreta modalidad de la limitada general, sino la diversificación del estatuto jurídico propio del empresario individual, inicialmente unitario en el Derecho español, si acertamos al insertar en este marco al mencionado operador económico. No se enriquecerá, de este modo, la tipología societaria, sino, más bien, la tipología del empresario individual, aunque, de lograrse el propósito del Gobierno, es posible que la nueva figura pase a ocupar, en la práctica, el lugar predominante dentro de esta última categoría, desplazando, de hecho, al empresario individual tradicionalmente sometido a responsabilidad ilimitada. En realidad, el hecho de equiparar al emprendedor, desde el punto de vista de la responsabilidad, con el socio de una anónima o de una limitada no constituye, en sentido estricto, una novedad, al menos por lo que se refiere a la perspectiva doctrinal [véase, entre otros, el trabajo de Gispert (1982)], ni tampoco legislativa, si se atiende a la figura, poco analizada entre nosotros, del "establecimiento mercantil individual de responsabilidad limitada" del Derecho portugués, regulada en ese país desde hace más de veinte años (Decreto-Ley 248/1986, de 25 de agosto). 
ejercicio de la libertad contractual por la vía societaria, cabría decir. Resulta más sencillo y más barato llevar a cabo la autorregulación por un camino externo, como el de los llamados pactos parasociales, a los que la LSC (artículo 29) denomina "pactos reservados", a pesar de que, en principio, carecen de eficacia frente a la sociedad, respecto de la que son, para la opinión todavía dominante, res inter alios acta. La suscripción de tales pactos, por algunos, por muchos $y$, en ocasiones, por todos los socios, puede ser, en tal sentido, una fórmula alternativa para el uso intensivo de la libertad contractual en un contexto, como el que ahora nos ocupa, en el que la celeridad de la constitución telemática priva a los estatutos de cumplir tal función. El principal inconveniente que se puede señalar a esta singular manifestación de la autonomía de la voluntad en el Derecho de sociedades es, desde luego, la ya advertida inoponibilidad erga omnes de su contenido; pero, del mismo modo, también debe verse como un inconveniente el fomento de la opacidad que a través de dichos pactos se consigue, por ser ellos, a diferencia de los estatutos y de acuerdo con la terminología legal, indudablemente reservados, esto es, ajenos al Registro mercantil y a la publicidad derivada de sus inscripciones, con lo que tal circunstancia supone para la tutela jurídica de los terceros.

No conviene dar a entender, con todo, que los pactos parasociales sean, a su modo, un elemento determinante desde el punto de vista tipológico, solo significativo en el contexto que venimos examinando. Como es bien sabido, los acuerdos entre socios al margen de los estatutos constituyen una realidad consustancial con el Derecho de sociedades en su moderna evolución, y puede rastrearse su presencia, así como la intensidad de la discusión doctrinal al respecto, a lo largo del pasado siglo ${ }^{21}$. En tal sentido, percibimos su presencia en todos los tipos de sociedades (en particular, de naturaleza capitalista), así como en sus diversas variedades, desde la pequeña sociedad de responsabilidad limitada hasta la gran sociedad anónima cotizada en Bolsa. Es evidente, no obstante, que desde hace bastantes años se observa una tendencia indudable a disminuir la opacidad de esta manifestación de la libertad contractual en el Derecho de sociedades, precisamente por venir referida a un tercero frente a los suscriptores, como es la sociedad, así como al conjunto heterogéneo de intereses articulado alrededor de ella. De ello es buena muestra la normativa en vigor respecto de las sociedades cotizadas (artículos 530-535 LSC), así como la publicidad de los protocolos familiares en las sociedades cerradas ${ }^{22}$. A la vez, va ganando terreno en la doctri-

21 Desde la perspectiva del Derecho francés, pero con indudable utilidad en otros ordenamientos, como el español, véase GuYon (2002), quien se ocupa, igualmente, del relieve de los estatutos sociales en el marco del régimen jurídico de las sociedades mercantiles en Francia.

22 En el ámbito de la empresa familiar, es decir, aquella empresa, constituida por lo común como sociedad, en la que la propiedad o el poder de decisión pertenecen total o parcialmente a un grupo de personas con vínculos de parentesco, bien sea por consanguinidad, bien sea por afinidad, entre sí, se habla de "protocolo familiar" para describir aquel acuerdo o conjunto de acuerdos entre socios o entre socios y terceros que viene a establecer, entre otros extremos, un modelo consensuado de toma de decisiones en el ámbito de la empresa. Hay acuerdo en la doctrina española en entender que el protocolo familiar es un ejemplo concreto de pacto parasocial y, por ello mismo, ajeno al Registro mercantil. Por ser las empresas familiares, habitualmente, sociedades mercantiles no cotizadas, quedan al margen de las reglas relativas a la publicidad de los pactos parasociales que afectan a las sociedades cotizadas. Para evitar, entonces, una excesiva opacidad en las empresas familiares, que son las mayoritarias en el tejido empresarial español, se promulgó el Real Decreto 171/2007, de 9 de febrero, por el que se regula la publicidad de los protocolos familiares. Dicha publicidad consiste en la posibilidad, no obligación, de que tales acuerdos accedan al Registro mercantil en los términos y condiciones que se establecen en el mencionado Real Decreto. 
na y, más tímidamente, en los tribunales, el criterio de dotar de eficacia frente a la sociedad a tales pactos, sobre todo cuando han sido suscritos por todos los socios (los ahora llamados pactos omnilaterales $)^{23}$.

\section{C) Autonomía de la voluntad y sociedades cotizadas}

(a) Consideraciones generales

Las anteriores reflexiones sobre la pérdida progresiva de relieve de los estatutos a la hora de establecer el régimen efectivo de la vida societaria no han de tomarse como afirmaciones de validez universal en el entero ámbito de las sociedades capitalistas. Si bien los pactos parasociales, como manifestación singular de la autonomía de la voluntad en el terreno societario, resultan operativos, con diferente alcance y régimen jurídico, claro está, en los diversos tipos y variedades de las sociedades de capital, los estatutos recuperan en ciertos ámbitos la significación que se les ha solido atribuir desde una perspectiva tradicional. Uno de los sectores en que ese fenómeno sucede de manera más evidente es el de las sociedades cotizadas, en el marco de la importante evolución que han experimentado en los últimos años y que ha traído consigo el establecimiento progresivo de especialidades en su régimen jurídico que, si bien, por el momento, no alteran su condición sustancial de sociedad anónima, contribuyen a darle un perfil cada vez más autónomo. Esa singularidad de la figura que nos ocupa ha supuesto su conversión, para ciertas corrientes de pensamiento, como el análisis económico del Derecho, en el modelo societario por antonomasia, trasladándose a otras figuras del Derecho de sociedades, por lo común cerradas, ideas y consideraciones que solo adquieren pleno sentido en el ámbito de las sociedades abiertas, como es la cotizada. Se trata de apreciar, por ello mismo, el alcance de la autonomía de la voluntad en la sociedad cotizada, cuestión esta cuyas diversas vertientes no han sido bien perfiladas hasta la fecha, quizá, entre otras cosas, por la frecuente invocación de la autorregulación, sin mayores matices, como instrumento idóneo para encauzar la solución de todos los problemas.

$Y$ es que el papel destacado que, en tiempos recientes, se ha atribuido a la sociedad cotizada en el contexto genérico del Derecho de sociedades, constituye, ciertamente, una llamativa novedad. Sin entrar ahora en el detalle de su régimen jurídico en la LSC, conviene decir que, hasta hace escasas fechas, la opinión dominante entre los juristas veía a nuestra figura como una mera variedad de la sociedad anónima. En tal sentido, le resultaban aplicables las normas integrantes del régimen general de esta última, si bien, por la amplitud de los intereses afectados por su actuación en el mercado, las posibles normas especiales que para ella pudieran dictarse habían de revestir, preferentemente, naturaleza imperativa. La evolución de las ideas en este ámbito ha sido sumamente rápida en los últimos años, viniendo condicionada, en buena medida, por el mayor protagonismo de las sociedades cotizadas en el mercado y en la actividad económica general. No se ha prescindido, con todo, del criterio antes señalado, sobre el relieve de las normas imperativas a la hora de articular su régimen jurídico, a pesar de los continuos embates que ha sufrido a manos de la autorregulación, como "fórmula mágica" del debate jurídico y económico más reciente. De la

$23 \mathrm{Al}$ respecto, Noval (2012). 
contraposición entre ambos planteamientos no se ha deducido todavía un criterio seguro a la hora de fijar las bases fundamentales de articulación normativa de nuestra figura. Parece consolidarse, no obstante, la idea de que la sociedad cotizada merece un estatuto jurídico diferenciado, superándose su mera consideración como variedad de la sociedad anónima. Este extremo se puede comprobar en muy distintos ordenamientos jurídicos, como puede ser, entre ellos, el español, donde se empiezan a dar pasos para el tratamiento cada vez más autónomo de la sociedad cotizada.

Ahora bien, la claridad de estas ideas no sirve para ilustrar de modo nítido el relieve concreto de la autonomía de la voluntad en el ámbito de nuestra figura. De seguirse la visión clásica, podría pensarse que su alcance efectivo fuera reducido; de optarse, en cambio, por el lema de la autorregulación, el resultado sería el contrario. Una cosa parece indudablemente cierta: el apogeo, cuando menos doctrinal, de las corrientes de pensamiento que propugnan la autorregulación como método no ha traído consigo la derogación del abundante arsenal normativo de naturaleza imperativa, que delimitaba, y todavía delimita en la actualidad, quizá con mayor empeño que en el pasado, el perfil jurídico de la sociedad cotizada. Cabría pensar, entonces, que el relieve efectivo de la autonomía de la voluntad en la sociedad cotizada sería menor del que conocemos en otras figuras del Derecho de sociedades, como la propia sociedad anónima. No creemos, sin embargo, que esto sea exactamente así y, más bien, la atenta observación de la realidad permite afirmar el alto relieve de la libertad contractual en el ámbito que ahora nos ocupa. Su correcta apreciación, con todo, requiere distinguir precisamente sus distintos niveles, evitando ver a la autorregulación como un fenómeno elemental, de trazo único.

(b) El significado de los estatutos en la sociedad cotizada: la autorregulación propiamente dicha o autorregulación individualizada.

Para empezar, el papel de los estatutos en una sociedad cotizada es sensiblemente más relevante de lo que se advierte en las sociedades cerradas, sobre todo si la constitución de estas últimas se ha llevado a cabo por medios telemáticos, con las consecuencias antes descritas. Los estatutos de una sociedad cotizada no suelen configurarse adoptando sic et simpliciter formularios redactados previamente, sino que, por la propia singularidad de la figura, son el resultado de un cuidadoso proceso de elaboración que se ve habitualmente enriquecido merced a la contribución de juristas expertos en Derecho de sociedades. Por otra parte, al lado de los estatutos encontramos otros documentos de redacción obligatoria, como son los reglamentos de la Junta general y del Consejo de administración, a los que la LSC dedica una cierta atención con motivo de la regulación de las sociedades cotizadas (artículos 512, 513, 528 y 529). Aun tratándose de textos cuyo significado jurídico es ciertamente diverso al de los estatutos sociales, su importancia para el funcionamiento de la figura que nos ocupa es considerable, en cuanto que son vehículo de expresión de la autonomía de la voluntad de los socios o, como hemos denominado aquí, de la autorregulación individualizada. Se trata, por tanto, de documentos elaborados desde la perspectiva singular de la sociedad cotizada a cuyos órganos sirven y en ellos se observa, asimismo, un cuidadoso uso de la libertad contractual en el marco de las tareas y cuestiones que les son propias. Gran parte de su contenido se vincula, por lo demás, con la materia del gobierno corpora- 
tivo (Corporate Governance), complementando o alterando el conjunto de recomendaciones que se contienen en los códigos de buen gobierno, que constituyen una nueva vertiente del relieve de la autonomía de la voluntad en las sociedades cotizadas ${ }^{24}$.

(c) Los códigos de buen gobierno: la autorregulación inducida.

De este modo, y al lado de la autorregulación propiamente dicha o autorregulación individualizada, encontramos lo que cabría denominar como "autorregulación inducida” y que, no obstante su gran relieve en los últimos años, solo representa una vertiente singular del principio general de la autonomía de la voluntad en las sociedades que ahora nos ocupan. No se trata aquí de la adopción o establecimiento por la concreta sociedad cotizada de unas determinadas cláusulas o pactos susceptibles de insertarse en sus estatutos o en los reglamentos de la Junta general y del Consejo de administración. Se trata, más bien, de la aceptación, en su caso, del conjunto de recomendaciones que se contienen en los llamados "códigos de buen gobierno" (Good Governance Codes), referidas, por lo común, a la gobernanza de las sociedades cotizadas, con particular incidencia en la organización, composición y funcionamiento del Consejo de administración.

A pesar de la pomposa denominación de "código", no cabe hablar, en tal caso, de normas vinculantes para las sociedades cotizadas, pues, como se acaba de señalar, no contienen preceptos de naturaleza imperativa, sino meras recomendaciones, de seguimiento voluntario por ellas. Solo cuando una determinada sociedad cotizada opte por no seguir alguna o varias de las concretas recomendaciones contenidas en el código surge un cierto elemento vinculatorio, derivado de la necesidad de explicar al mercado el porqué de dicha falta de seguimiento (la conocida regla comply or explain). Esta circunstancia es la que permite justificar la terminología aquí empleada de "autorregulación inducida", ya que, preservada, en su aspecto más elemental, la libertad de la sociedad para acoger las "normas" del código, su aceptación, en última instancia, es un mero acto ratificatorio, cabría decir, de lo hecho por otros, por los redactores del código, en suma.

La puesta en marcha de los códigos de buen gobierno desdibuja, indudablemente, el relieve de la autonomía de la voluntad en las sociedades cotizadas, pero no carece, sin embargo, de significación para ellas. Es más, algunas de sus recomendaciones han adquirido carta de naturaleza al ser recogidas en normas jurídicas imperativas, al convertirse en una suerte de "costumbre" societaria en ciertos casos, y como consecuencia, en fin, del hecho de entrelazarse con la autorregulación propiamente dicha mediante su consignación en textos como los reglamentos de la Junta general y del Consejo de administración, antes mencionados. Con todo, la intensidad y la duración de la crisis económica han terminado por re-

24 La elaboración de códigos de buen gobierno es una práctica extendida por todo el mundo, al hilo, entre otros extremos, de la difusión de las ideas propias del análisis económico del Derecho en el marco de las sociedades cotizadas, orientado, en este punto, a restringir al máximo posible las normas imperativas, dando un mayor espacio a la "autorregulación" derivada de las recomendaciones contenidas en dichos códigos. En España hay que aludir al Código unificado de buen gobierno, elaborado en 2006 a partir de la armonización y actualización de las recomendaciones de los Informes Olivencia (1998) y Aldama (2003) sobre buen gobierno de las sociedades cotizadas, también llamado "Código Conthe" por el apellido del entonces Presidente de la Comisión del Mercado de Valores (Manuel Conthe Gutiérrez). 
lativizar el valor más significativo con el que se presentaban los códigos de buen gobierno, esto es, con su carácter de recopilación de recomendaciones en el sentido que se acaba de señalar.

Por tal circunstancia, pueden entenderse los diversos intentos de superar el planteamiento de "autorregulación inducida" típico de tales códigos, para llegar a una ordenación más precisa, y, a la vez, de mayor carácter vinculante, para las sociedades cotizadas ${ }^{25}$. No se trata solo de "cumplir" con lo en ellos establecido mediante la asunción formal de sus recomendaciones, sino de conseguir su efectiva concreción en el funcionamiento de las sociedades cotizadas. Para algunos autores, un buen elemento a tal efecto sería la introducción en los estatutos de una cláusula de sometimiento a arbitraje para la resolución de los conflictos societarios $^{26}$. De este modo, se terminaría produciendo una estrecha conexión entre los diferentes niveles de autorregulación, otorgando un papel determinante a los estatutos como expresión de la autorregulación individualizada en la línea del clásico principio de autonomía de la voluntad, superándose así las conocidas insuficiencias de la técnica de ordenación característica de los códigos de buen gobierno ${ }^{27}$.

(d) El significado de los pactos parasociales en la sociedad cotizada: la autorregulación restringida y heterónoma.

Ya se ha indicado con anterioridad que los pactos parasociales extienden su relieve a todas las sociedades de capital. También en las sociedades cotizadas han adquirido considerable importancia, hasta el extremo de que el legislador español, de forma inusual, les ha dedicado una llamativa atención en el marco de las reformas legislativas acaecidas en los últimos años sobre las mismas. En la actualidad, ese régimen se encuentra situado en los artículos 530-535 LSC y su objetivo básico es dar transparencia, en beneficio del mercado, a los más relevantes pactos parasociales que se concluyan en relación con las sociedades cotizadas $^{28}$. Sin entrar ahora en el detalle de dicha normativa, conviene resaltar el extraordinario relieve de dichos pactos en el ámbito tipológico propiamente dicho; y es que, a priori, cabría dudar de su verdadera utilidad para las sociedades cotizadas, como consecuencia, entre otras cosas, de la elevada cifra de capital propia de estas sociedades, del amplio número de socios que las forman y de su carácter plenamente abierto.

Pero, como también es sabido, no todas las sociedades cotizadas responden fielmente al modelo de las grandes corporaciones que, de manera sucinta, se acaba de describir. En tal sentido, aquellas que escapan a tal modelo constituyen, no obstante su condición de sociedades abiertas, campo abonado para el ejercicio de la autonomía de la voluntad de algunos socios relevantes por el singular camino de los pactos parasociales. Pueden entenderse, en

\footnotetext{
25 Véase, en tal sentido, European Commission (2011). La bibliografía sobre gobierno corporativo es, ciertamente, enorme; como aportaciones recientes pueden verse los trabajos de Clarke (2011) y Hopt (2011).

26 En este sentido, Fernández (2012) p. 124.

27 La cuestión se plantea en términos similares respecto de otro fenómeno de nuestro tiempo, también de influjo considerable en las sociedades de capital, como el de la responsabilidad social de la empresa, algunos de cuyos objetivos esenciales se reflejan, también, en "códigos" de valor equivalente al de los mencionados en el texto. Al respecto, véase EmBid (2006) pp. 65-66.

28 En relación con la inobservancia del régimen de transparencia, véase YANES (2011).
} 
esta línea, las cautelas establecidas en la LSC, así como la terminología aquí empleada; hablar, entonces, de "autorregulación restringida y heterónoma" significa, en esencia, describir que la elaboración de las cláusulas de un pacto parasocial relativo a una sociedad cotizada es patrimonio exclusivo de algunos socios relevantes de la misma que, de este modo, están en condiciones de influir de modo significativo en su organización y funcionamiento ${ }^{29}$.

\section{D) Balance provisional del significado de la autonomía de la voluntad en el}

\section{Derecho de sociedades de capital}

La sintética exposición efectuada hasta el momento permite elaborar un balance, siquiera provisional, del alcance concreto de la autonomía de la voluntad en el ámbito de las sociedades de capital. Quizá lo más destacado de dicho balance consista en una llamativa paradoja: la autonomía de la voluntad, al menos la que se expresa en las cláusulas estatutarias, disfruta de un considerable protagonismo en la sociedades de mayor dimensión empresarial, normalmente cotizadas, y va perdiendo relieve, en beneficio de fórmulas estatutarias estándar, en las sociedades de menor tamaño. Esta constatación es, en verdad, paradójica, porque la tradición heredada en el tema que nos ocupa postulaba, sin demasiadas dudas, la solución contraria. Y es que, con arreglo a un planteamiento clásico, es en la sociedad de pocos socios, sobre todo si se configura como sociedad de responsabilidad limitada, donde por razones, desde luego, de lógica jurídica, pero también de carácter práctico, habría de alcanzar la libertad contractual un mayor desarrollo. Para las sociedades que gestionan empresas de gran dimensión, en cambio, la autonomía de la voluntad ocuparía un lugar relativamente subordinado al régimen legislativo, el cual, por las propias circunstancias de la figura regulada, habría de ser imperativo, al menos en sus aspectos más relevantes.

A pesar de la exactitud, cuando menos teórica, de algunas de estas afirmaciones, es lo cierto, como hemos tenido ocasión de apreciar, que al hilo de ciertas corrientes de pensamiento, de un lado, y de la acelerada evolución tecnológica, de otro, la libertad contractual que se refleja en los estatutos ha experimentado una mutación considerable, susceptible de alterar, por otra parte, saberes consolidados en el Derecho de sociedades. El caso de la sociedad de responsabilidad limitada, en concreto, constituye una prueba relevante de lo que venimos diciendo. Si de manera tradicional, su constitución y su articulación estatutaria por los socios representaban campo privilegiado de ejercicio de la libertad contractual, en fechas recientes estamos asistiendo a una intensificación legislativa de dicho planteamiento. El ejemplo del Codice civile italiano, mediante la reforma de 2003, es, tal vez, el exponente europeo más aquilatado de semejante tendencia. Con todo, la realidad está desmintiendo, por diversos caminos, las razones que llevaron al legislador, y no solo en Italia ${ }^{30}$, a flexibilizar hasta límites extraordinarios su régimen normativo. Y lo hace de la mano de los ins-

29 Que los pactos parasociales tienen un relieve extraordinario en las sociedades cotizadas lo acaba de confirmar la reciente Ley 1/2012, de 22 de junio, cuando alude a ellos en el marco de la reforma del artículo 60 LMV que se lleva a cabo en su disposición adicional primera, apartado tres, que reinstaura la licitud de las cláusulas de blindaje en dichas sociedades, con la consiguiente reforma de los artículos 188 y 527 LSC.

30 De manera que la extraordinaria libertad contractual ofrecida a la sociedad limitada por el legislador italiano desde la reforma de 2003 no ha pasado del texto normativo a la realidad societaria. Al respecto, Di CATALdo (2011). 
trumentos que nos son ya conocidos: la utilización de formularios estándar y la irrupción progresiva de las nuevas tecnologías, de difícil convivencia, por otra parte, con el ejercicio intensivo de la autonomía de la voluntad.

Es verdad, no obstante, que la autonomía de la voluntad termina encontrando caminos por los que manifestarse, a fin de dotar a la sociedad de ciertos caracteres singulares que permitan "personalizar" su configuración interna. Se trata, como también sabemos, de los pactos parasociales, cuyo relieve se aprecia en todas las sociedades de capital, si bien la política legislativa muestra, de nuevo, una importante diferencia entre las sociedades cerradas y las sociedades cotizadas. Si en estas últimas, el legislador, por razones de tutela del mercado de valores, intenta hacer transparentes dichos acuerdos entre socios o, al menos, los más destacados, en las sociedades cerradas (y muy especialmente en la sociedad de responsabilidad limitada), los pactos parasociales, en los que se plasma, de hecho, la constitución "auténtica" de la sociedad frente a la constitución formal o aparente, derivada de las cláusulas estatutarias, se convierten en negocios opacos, inaccesibles, por regla general, a los terceros, no obstante su trascendencia para la organización y el funcionamiento de la sociedad.

Se empieza a esbozar, de este modo, y a través del relieve que, en cada figura, llegue a tener la autonomía de la voluntad, un Derecho de sociedades progresiva y paradójicamente fragmentado, una suerte de Derecho de sociedades "a varias velocidades". En lo que atañe a las sociedades cotizadas, la conjunción de un régimen de naturaleza sustancialmente imperativa y del ejercicio intensivo de la autonomía de la voluntad, tanto por vía estatutaria como a través de los pactos parasociales, sometidos estos últimos a una notable transparencia, nos encontramos con el fragmento más sólido y más auténtico de Derecho de sociedades, bien que adaptado a una modalidad societaria a medio camino entre el Derecho privado y la ordenación pública del mercado de valores. En lo que se refiere, en cambio, a las sociedades cerradas, asistimos a una progresiva objetivación de su naturaleza, a través del habitual recurso a las cláusulas estándar de los estatutos y por el uso, cada vez mayor, de las nuevas tecnologías con motivo de su constitución. Ello reduce su significado estricto como personas jurídicas de Derecho privado y las aleja del núcleo clásico del Derecho de sociedades para convertirlas en figuras burocratizadas, prácticamente idénticas entre sí, al menos en su configuración aparente ${ }^{31}$.

31 El hecho de que el presente trabajo se limite a las sociedades de capital en el vigente Derecho español justifica que no se haya aludido en el texto a las sociedades de personas, a pesar de que algunos de sus principios han inspirado el régimen de la sociedad de responsabilidad limitada. Como es sabido, el nacimiento de esta última como figura societaria típica responde al deseo de combinar la libertad contractual característica de las sociedades de personas con la ausencia de responsabilidad de los socios por las deudas sociales, propia de la sociedad anónima. También es cierto que, en el marco que nos ocupa, la libertad contractual ha sido el instrumento esencial para "personalizar" en lo posible el contenido normativo básico de las figuras capitalistas, desde el punto de vista de su concreta configuración organizativa. La evolución descrita en el texto pone algunos reparos en el presente a esta orientación tradicional, sin que los distintos tipos de sociedades de personas jueguen, en la mayoría de los países, y desde luego en España, un papel relevante a la hora de buscar el modelo societario idóneo para una determinada empresa. Es verdad, no obstante, que existen ordenamientos europeos, como el alemán, donde las sociedades de personas disfrutan de un protagonismo relevante en el terreno empresarial, sirviendo, además, la autonomía de la voluntad para articular figuras diversas a través de las cuales ha podido evolucionar de manera destacada el Derecho de sociedades de aquel país. El caso de la sociedad comanditaria cuyo socio colectivo es una sociedad de responsabilidad limitada (la Gesellschaft mit beschränkter Haftung \& 


\section{LAS LÍNEAS MAESTRAS DE LA REGULACIÓN DE LAS SOCIEDADES DE CAPITAL EN LA LSC}

\subsection{LAS Figuras REguladas}

Aun dentro de sus limitaciones, el repaso que se ha dado en el epígrafe anterior a las fuentes del Derecho de sociedades de capital ha permitido apreciar su alcance dentro de la LSC, tanto en lo que se refiere, de un lado, a su dimensión sustancial, o sea, a los tipos básicos regulados, como, de otro, en lo que atañe al relieve de algunas de sus variedades. Parece conveniente, con todo, profundizar algo más en esta cuestión, realmente determinante, al menos en teoría, para un cuerpo normativo de las características de la LSC. Como punto de partida, hay que recordar, no obstante, el hecho de que la LSC no es una pieza legislativa concebida de modo singular, sino, según es bien sabido, un texto refundido, cuyo contenido normativo y tipológico viene condicionado de manera insuperable por las leyes y normas objeto de refundición en ella. Por tal motivo, las sociedades de capital reguladas en dicha ley son, como figuras esenciales de esta categoría societaria, las mismas que anteriormente gozaban de tal condición, es decir, la sociedad anónima, la sociedad de responsabilidad limitada y la sociedad comanditaria por acciones. Su inserción en la LSC se ha llevado a cabo, en lo sustancial, de manera individualizada; es decir, cada tipo societario ha mantenido su particular perfil, aportando al contenido de la LSC el concreto régimen jurídico del que estaba dotado con anterioridad a su promulgación. Es cierto, no obstante, que, de acuerdo con el mandato de refundición, el legislador ha armonizado aspectos concretos de su tratamiento, suprimiendo, de este modo, algunas diferencias carentes de justificación, sobre todo en lo que se refiere a las sociedades anónimas y de responsabilidad limitada.

Con todo, la regulación de las tres sociedades mencionadas no agota el contenido de la LSC, ya que también se contempla en ella, como no podía ser de otro modo, de acuerdo con el mandato de refundición, el régimen particular de algunas variedades o modalidades de los tipos básicos antes citados. Se trata de la sociedad limitada nueva empresa (Título XII) y la sociedad anónima cotizada (Título XIV), las cuales, al menos por el momento, no constituyen formas societarias autónomas sino meras especializaciones de la limitada y la anónima, respectivamente. El distinto alcance de esa especialización, así como la diversa trascendencia de dichas figuras en la realidad empresarial española les otorga un relieve del todo diferente en el seno de la LSC, permitiendo avizorar el incremento de la especialidad propia de la sociedad cotizada, y su reducción o incluso anulación en lo que atañe a la sociedad limitada nueva empresa ${ }^{32}$.

\footnotetext{
Compagnie Kommanditgesellschaft, conocida por su siglas $G m b H$ \& $C o K G$ ) constituye, a tal efecto, el supuesto más conocido, aunque existe aquí una gran creatividad de la práctica, asistida, eso sí, por el consejo permanente de los juristas expertos en Derecho de sociedades, de modo que la figura societaria definitivamente organizada se adecue de la mejor manera posible a las necesidades de los socios.

32 Así como la opinión expresada en el texto sobre la sociedad cotizada parece corresponder plenamente con su evolución legislativa y con su relieve económico, no es seguro que termine sucediendo lo mismo respecto de la sociedad limitada nueva empresa, afectada por algunas de las reformas llevadas a cabo en la LSC. Véase, al respecto, Castañer (2012).
} 
Hay que aludir, por último, a la regulación de la sociedad anónima europea domiciliada en España, cuya presencia en la LSC era, del mismo modo, inevitable (Título XIII). Su condición de tipo societario de Derecho europeo no oculta su estrecha vinculación con el régimen general de la sociedad anónima en nuestro ordenamiento, si bien con una serie de particularidades y matices que le dan una significativa autonomía respecto de la figura nacional. Así sucede, por ejemplo, con la posibilidad de organizar la administración de la sociedad europea de acuerdo con el modelo dualista (artículo 476), lo que convierte a dicha figura, apenas utilizada en la realidad empresarial española ${ }^{33}$, en una estructura jurídica compleja necesitada de cuidadoso análisis.

\subsection{LA ORDENACIÓN BÁSICA DE LOS TIPOS SOCIETARIOS}

\section{A) El problema}

Descrito sumariamente el repertorio de figuras reguladas en la LSC, resulta necesario analizar el planteamiento de tipología societaria contenido en dicha ley. Sin entrar, por el momento, en mayores averiguaciones, parece lógico pensar que una ley intitulada de "sociedades de capital" ha de contener algunas orientaciones sobre una materia tan relevante. Y ello con independencia de si el legislador las ha formulado expresamente, lo que no ha sido el criterio predominante en el Derecho español al afrontar, en el pasado, su regulación, o si, más bien, cabe deducirlas del conjunto de la regulación. Es claro, desde luego, que la simple enumeración de los tipos y de sus variedades no permite responder a la cuestión ahora planteada. Al fin y al cabo, el tratamiento legislativo de una serie de formas jurídicas en una ley de sociedades de capital nada dice sobre los principios relativos a su coexistencia, sin perjuicio, claro está, de reconocer que la recepción por el legislador de un catálogo amplio de tipos societarios permite a los particulares una libertad de elección igualmente extensa.

Pero del mismo modo que acabamos de afirmar la necesidad de considerar la cuestión relativa a las figuras o tipos de sociedades en la LSC, podría decirse, a renglón seguido, que se trata de un asunto redundante, no necesitado de un análisis especial como consecuencia, esencialmente, de que dicha ley no es, como tantas veces se ha advertido en este trabajo, una pieza legislativa autónoma sino un mero texto refundido. Por tal razón, cabría seguir sosteniendo que no hay lugar para innovaciones significativas en dicha materia, siendo la única opción posible para el legislador la de la estricta continuidad, más allá de lo que pudiera llegar a suponer el mandato de regularizar, aclarar y armonizar los textos legales

33 A diferencia de lo que sucede con otros países de la Unión Europea, como es, singularmente, el caso de Alemania. Allí el desarrollo de la sociedad anónima europea responde, quizá, al deseo de numerosas empresas (generalmente, las de mayor tamaño) de eludir las estrictas prescripciones del ordenamiento alemán sobre cogestión laboral, que traen consigo inevitablemente la presencia de los representantes de los trabajadores en el Consejo de vigilancia de la sociedad anónima en términos casi paritarios con los representantes del capital. Como en la sociedad anónima europea su estructura administrativa es disponible, se puede constituir dicha figura con arreglo al modelo monista de administración social, lo que implica prescindir del Consejo de vigilancia y, de paso, de la cogestión laboral. No debe ignorarse que, en los últimos años, han sido numerosos los juristas alemanes que ven en esta institución un inconveniente para la conversión del país en una relevante plaza financiera, retrayendo a los inversores extranjeros. 
de necesaria refundición, cuando se puso en marcha la tarea de elaborar la LSC. Dicho de manera resumida, la reflexión sobre la tipología societaria en la LSC, de acuerdo con este planteamiento, serviría únicamente para reiterar lo ya sabido en torno al significado, alcance y relaciones mutuas de los tipos societarios de las sociedades de capital existentes en el ordenamiento jurídico español.

\section{B) La "cuestión tipológica" en la LSC: aspectos concretos y orientaciones generales}

Son varias las razones que, a nuestro juicio, invalidan este criterio y que, a la vez, justifican la necesidad de llevar a cabo una reflexión amplia y rigurosa sobre el tema en estudio tras la entrada en vigor de la LSC ${ }^{34}$. Aunque no es este el lugar idóneo para semejante reflexión, intentaremos señalar algunos de sus elementos más destacados, centrándonos no tanto o no solo en el contenido dispositivo en la ley, sino, sobre todo, y quizá de modo paradójico, en su exposición de motivos. En ella se encuentran una serie de consideraciones sobre la ordenación de los tipos societarios que parecen mirar no tanto al presente del problema en el Derecho español, sino, en particular, al futuro, mediante la fijación de una serie de criterios susceptibles de ilustrar las futuras reformas legislativas que se acometan en el ámbito de las sociedades de capital.

Para empezar, debe señalarse que hay algunas innovaciones relevantes en el seno de la propia LSC, como consecuencia del propósito de aclarar y armonizar los textos refundidos al que se acaba de aludir. Si en numerosas ocasiones las reformas llevadas a cabo respecto de estos últimos se insertan sin problema en el marco de las finalidades pretendidas por la refundición, en otras, en cambio, constituyen auténticos excesos del legislador-refundidor (los ya mencionados ultra vires), de cuya legitimidad puede dudarse con fundamento. De entre los varios supuestos que pueden tener consistencia tipológica, vayan o no más allá del mandato de refundición, bastará con mencionar ahora ciertos cambios introducidos en el régimen de la Junta general, la extrapolación de los deberes de los administradores a las sociedades distintas de la anónima, o, en fin, las nuevas pautas en materia de separación y exclusión de socios, trascendiendo la anterior visión de la salida, voluntaria o forzosa, de los socios del marco estricto de la sociedad de responsabilidad limitada.

Siendo estas alteraciones indudablemente relevantes, el sesgo de mayor intensidad se encuentra, como ya se ha señalado, en la exposición de motivos de la LSC. No es fácil adivinar la razón que ha llevado al legislador a situar en dicho ámbito una serie de consideraciones que, centradas en el debate tipológico, no aparecen primariamente referidas al contenido de la ley a la que sirven de antesala. Hay, con todo, un precedente cercano para semejante actitud y es la delimitación de la sociedad de responsabilidad limitada contenida en la Ley de sociedades de responsabilidad limitada (en adelante, LSRL), de 1995, derogada, a la sazón, por la LSC. Quizá pueda pensarse que, ante la eliminación de esa relevante toma de postura en materia de ordenación societaria que la citada derogación traía inevitablemente consigo, haya decidido el legislador ofrecer un conjunto de reflexiones susceptible de orientar el debate en un asunto tan significativo. Del mismo modo, y por referirse más al futuro del problema que a su situación actual, cabe también considerar que el legislador

34 Sobre esta cuestión, véase EMBid (2011). 
ha pretendido dejar fijado el "terreno de juego" en dicha materia, anticipándose a matices divergentes, cualquiera sea el sentido de su orientación.

En cualquier caso, y sea lo que fuere en cuanto al fundamento y razón de ser del reseñado modo de actuar, debe destacarse la considerable novedad que supone el punto de vista adoptado por el legislador. De manera sintética, puede decirse que se destaca con intensidad la singularidad de la sociedad cotizada, solo parcialmente expresada en la parte dispositiva de la LSC, proponiéndose al mismo tiempo la práctica "fusión" de la sociedad de responsabilidad limitada con la sociedad anónima cerrada. Al margen del acierto que, en su caso, pueda concurrir en este planteamiento dualista, lo relevante es que no parece ser esa, exactamente, la situación que cabe deducir de la LSC y, menos aún, la que existía con anterioridad. Es cierto, desde luego, que el Derecho positivo español nunca ha afrontado de manera consecuente el problema tipológico, lo que ha traído consigo numerosas dudas y contradicciones desde que se inició, a mediados del siglo pasado, la etapa "moderna" de la normativa sobre sociedades de capital. La exposición de motivos de la LSRL de 1995 fue, como ya se ha advertido, la primera manifestación rigurosa en la materia, si bien el objetivo del legislador consistió en delimitar el perfil de la sociedad de responsabilidad limitada, enunciando y describiendo sus características principales.

Sin ser del todo unánime el criterio de la doctrina al respecto ${ }^{35}$, parecía que el Derecho español de sociedades de capital se orientaba, con anterioridad a la LSC, hacia un criterio tipológico de tres niveles: la sociedad limitada, la sociedad anónima cerrada y la sociedad anónima abierta, cotizada en Bolsa. No es seguro que el contenido dispositivo de la LSC haya superado este esquema e introducido, en línea con su preámbulo, un modelo dualista, no obstante los cambios, ya señalados con anterioridad, que dentro de ella traen consigo una considerable renovación en la materia. Por esta razón, resulta más llamativa, si cabe, la amplitud e intensidad con la que el legislador se ocupa en la exposición de motivos de la LSC de la ordenación general de los tipos societarios, a la vista de la relativa incompatibilidad que se advierte entre su contenido y la disciplina específica contenida en la segunda. Sería posible hablar, así, de una serie de proposiciones ultra vires, dentro del preámbulo de la LSC, por parte del legislador, cuya trascendencia o, más precisamente, cuya posibilidad de perdurar en el tiempo, ha de ser relativizada a la vista de la "volatilidad", cabría decir, de la disciplina normativa en materia de sociedades de capital. Del mismo modo que el paso del tiempo desvanece, al menos en parte, la "voluntad de provisionalidad" con la que la propia exposición de motivos califica la reforma legislativa producida con la LSC, no obstante sus sucesivas modificaciones posteriores, también puede reducirse el relieve que el legislador ha querido atribuir a sus reflexiones tipológicas, así como a la previsión que, con cierta ligereza, ha querido formular en punto a la evolución inmediata del Derecho español de sociedades de capital.

En cualquier caso, el jurista, cualquiera sea la posición en la que se encuentre, ha de partir de la situación que se deduce del contenido dispositivo de la LSC a la hora de analizar y resolver los conflictos de intereses surgidos en la práctica y que tengan entre sus componentes alguno que afecte a la materia que nos ocupa. Su exposición de motivos, a

35 Véase, por muchos, la detenida reflexión de Fernández (2010). 
diferencia del papel que jugó en su día el preámbulo de la LSRL, no puede servir como elemento interpretativo determinante a la vista de la incompatibilidad existente entre una buena parte de lo que en ella se dice y la concreta disciplina establecida en la propia ley. El tiempo dirá si, con independencia de su calidad técnica, las reflexiones sobre la cuestión tipológica contenidas en la exposición de motivos de la LSC van a influir efectivamente en la política legislativa sobre las sociedades de capital o quedarán, sin más, en un mero brindis al sol.

\subsection{El esquema de REgulación}

Una vez descrita de manera sumaria la incidencia de la LSC en la ordenación básica de los tipos societarios, resulta necesario dedicar algunas líneas al modo en que dicha ley afronta la regulación de las sociedades de capital desde el punto de vista sistemático. Aunque, en abstracto, eran posibles muy diversas maneras de llevar a cabo esta crucial tarea, desde un esquema elemental, consistente en reproducir, sin más, la situación legislativa anterior, hasta otro de máximo sistematismo, pasando por varias fórmulas intermedias, no resultaba fácil hacerlas compatibles con los imperativos propios de la refundición. Y es que el "pie forzado" con el que se concibió la LSC suponía restricciones considerables al proceder legislativo, con independencia de que fuera posible otro camino. Excluida la fórmula del esquema elemental, que traería consigo la irrelevancia absoluta de la refundición, debían considerarse excluidas, asimismo, otras modalidades de ordenación sistemática, como la de mayor ambición en dicho ámbito que se identificaría con la división del material normativo en una parte general y otra u otras de carácter especial ${ }^{36}$. Conviene tener en cuenta que la mayor parte de los preceptos susceptibles de incluirse en aquella serían preceptos nuevos, ajenos, en principio, al sentido y al fin que inspiraron la refundición normativa o, en todo caso, generalizaciones de normas que, en la situación anterior, correspondían a la regulación específica de un concreto tipo societario.

En este punto, hay que aludir, de nuevo, a la exposición de motivos de la LSC, que, aquí con toda legitimidad, a nuestro juicio, intenta explicar el modo en que se ha llevado a cabo la tarea de ordenar sistemáticamente el régimen de las sociedades de capital. La explicación, con todo, no resulta fácil de formular por la complejidad del criterio adoptado para llevar a cabo la regulación de las sociedades de capital. En dicha orientación, y sobre la base de un iter abstracto, aplicable, en sentido amplio, a cualquier sociedad de capital, se entrecruzan numerosas regulaciones generales, comunes, por tanto, a todos los tipos, sobre asuntos específicos, con multitud de preceptos solo aplicables a alguno de ellos. Este criterio dificulta la comprensión de la LSC por los juristas y, a falta de una toma de postura concreta por el legislador, obliga a formular algunas reglas interpretativas que superen las numerosas dudas suscitadas por la ordenación sistemática de la LSC. Entre ellas podría aventurarse una, que implicaría interpretar estrictamente las normas dictadas por el legislador para un determinado tipo societario; no es desde luego la más idónea para un ámbito

36 De acuerdo con lo que se establecía en la Propuesta de Código de sociedades mercantiles (2002) preparada por la Comisión General de Codificación. 
como el Derecho de sociedades de capital que requiere dosis considerables de flexibilidad y de adaptación a la realidad del tráfico.

Y no lo es, tampoco, desde la perspectiva tipológica de la exposición de motivos que promovía, como se recordará, un modelo de corte dualista (sociedad abierta-sociedad cerrada) más allá de la clásica división en tipos característica del Derecho español. En tal sentido, mal se acomoda esa interpretación estricta, que impide extender, por ejemplo, normas dictadas exclusivamente para la sociedad de responsabilidad limitada (como la exclusión del derecho de voto en situación de conflicto de intereses, a la que se refiere el artículo 190 LSC) a la sociedad anónima cuando haya "identidad de razón". Con todo, la mencionada interpretación parece consolidarse entre la doctrina y la jurisprudencia, sin duda, como un elemento de seguridad jurídica y, a la vez, de respeto, cuando menos formal, a la ordenación sistemática, ciertamente compleja, establecida por el legislador ${ }^{37}$. La evolución emprendida hacia un texto legislativo más completo y ambicioso que la LSC, en la línea de la Propuesta de Código de sociedades mercantiles, de 2002, será quizá la circunstancia que pueda llegar a alterar el reseñado planteamiento. Por el momento, y en tanto no se supere la "voluntad de provisionalidad" de la LSC, no parece fácil soslayar la línea interpretativa expuesta.

\section{CONCLUSIONES}

La LSC es la pieza legislativa básica del Derecho español de sociedades de capital. La importancia de esta regulación no necesita ser resaltada, dado que en ella se ha refundido la normativa singular que, con carácter previo, regulaba en España las distintas formas de sociedades de capital, incluyendo no solo los tipos básicos (anónima, responsabilidad limitada y comanditaria por acciones), sino también sus principales modalidades (sociedad limitada nueva empresa y sociedad cotizada) y alguna figura societaria de Derecho europeo, como la sociedad anónima europea.

Por su naturaleza de texto refundido, la LSC no constituye un ordenamiento de nueva planta de los tipos societarios regulados, si bien no faltan innovaciones y cambios relevantes en algunos puntos significativos de su régimen jurídico, susceptibles de afectar a materias tan significativas como las de naturaleza tipológica. Con todo, la LSC no puede considerarse la regulación "definitiva", si cabe hablar en estos términos, de las sociedades de capital en el Derecho español; se trata, meramente, de una "etapa intermedia" hasta que se consiga elaborar el Código o Ley general de dichas figuras societarias anunciado por su exposición de motivos.

A pesar de ser una norma propia del ordenamiento jurídico español, la renovación de la LSC, intensa hasta hoy, no obstante sus escasos dos años de vigencia, no ha procedido del legislador nacional en exclusiva. La integración de España en la Unión Europea desde finales del pasado siglo supone, como uno más de sus Estados miembros, el sometimiento

\footnotetext{
37 En esta línea, véase, por ejemplo, la resolución de la DGRN de 10 de octubre de 2011, conforme a la cual el suplemento (rectius, complemento) de convocatoria de la Junta general, al que se refiere el artículo 172 LSC, es aplicable a las sociedades anónimas, no a las limitadas.
} 
a las normas jurídicas provenientes de esta organización supranacional, entre las que se cuentan, y con gran relieve, las relativas al Derecho de sociedades. Al lado, por tanto, de las fuentes internas de renovación normativa, concurre esta singular "fuente externa", cuya importancia, tras algunos años de atonía, se ha incrementado en nuestro siglo de manera considerable, completada, entre otros extremos, por la doctrina emanada del Tribunal europeo de Justicia, de extraordinario relieve para el Derecho de sociedades, al haber facilitado enormemente la libertad de establecimiento y la "movilidad", en suma, de esas personas jurídicas en el ámbito de la Unión Europea.

La autonomía de la voluntad, tan relevante, desde el punto de vista tradicional, en el Derecho de sociedades, asume hoy un papel no del todo homogéneo si se la considera desde la perspectiva de los distintos tipos y modalidades societarias que componen el actual Derecho de las sociedades de capital. Y ello ha de ser valorado en una doble vertiente: en la configuración estatuaria de cada sociedad, de un lado, y en la utilización de los llamados pactos parasociales.

Por lo que se refiere a los estatutos sociales, se observa su progresiva pérdida de relieve, como elemento diferenciador, en las sociedades cerradas, tanto anónimas como de responsabilidad limitada, por el frecuente recurso a los formularios estándar y a su cada vez más frecuente constitución por medios telemáticos. El fenómeno contrario se aprecia, en cambio, en las sociedades cotizadas, donde los estatutos son objeto de cuidadosa elaboración y representan, entonces, una fórmula de extraordinaria importancia para delimitar el significado de cada figura, mediante un ejercicio intensivo de la autonomía de la voluntad.

Por lo que se refiere a los pactos parasociales, la realidad práctica de las sociedades de capital en España pone de manifiesto su extraordinaria importancia como expresión, en cada caso, de la libertad contractual de los socios, teniendo en cuenta que, como fenómeno puramente negocial, constituye un pacto reservado y resulta, en principio, inoponible a la sociedad. Aunque su uso se observa en todas las figuras y modalidades de sociedades de capital, en algunas de ellas, como en las sociedades cotizadas, la importancia de sus efectos ha obligado al legislador a establecer específicas reglas de transparencia. No sucede así, como regla general, en las sociedades cerradas, donde su importancia para la organización y funcionamiento de la sociedad, no se ve acompañada de un adecuado sistema de disclosure.

El escaso tiempo transcurrido desde la entrada en vigor de la LSC impide ofrecer una valoración fundada de su efectivo relieve en la regulación de las sociedades de capital dentro del Derecho español. Con independencia de las críticas que, desde la política legislativa, pudieron formularse en el pasado a su promulgación, la vigencia de la LSC parece hoy un hecho indiscutible, a pesar de la paradójica "voluntad de provisionalidad" con la que su exposición de motivos la ha querido distinguir, así como de las numerosas reformas que la han afectado. Si algunas de ellas eran obligadas, como consecuencia de la pertenencia de España a la Unión Europea, otras quizá hubieran necesitado mayor meditación.

Conviene evitar, en beneficio de la seguridad jurídica y de la justicia, la tentación reformadora, a la que resulta tan sensible el legislador español, adoptada, tal vez, como instrumento relevante para luchar contra la grave crisis económica del presente. La solución se encuentra, más bien, en no demorar en exceso la elaboración del anunciado Código de sociedades mercantiles, a fin de conseguir, cuanto antes, la mayor estabilidad posible para 
este sector del ordenamiento jurídico, de tan extraordinario relieve para el ejercicio de la actividad empresarial en el mercado.

\section{BIBLIOGRAFÍA CITADA}

Alonso ledesma, Carmen; Alonso Ureba, Alberto; Esteban Velasco, Gaudencio (2011): La modernización del Derecho de sociedades de capital en España. Cuestiones pendientes de reforma (Cizur Menor Aranzadi), 537 pp.

Broseta Pons, Manuel; Martínez Sanz, Fernando (2011): Manual de Derecho Mercantil (Madrid, Tecnos, 18 ed.), tomo I, 656 pp.

Castañer Codina, Joaquim (2012): "Reformas en materia de sociedad nueva empresa", en: Rodríguez Artigas, Fernando; Farrando Miguel, Ignacio; González CastiLLA, Francisco (eds.), Las reformas de la Ley de sociedades de capital (Real Decreto-ley 13/2010, Ley 2/2011, Ley 25/2011 y Real Decreto-ley 9/2012) (Cizur Menor, Aranzadi), pp. 319-353.

Clarke, Donald (2011): "Nothing but Wind? The Past and Future of Comparative Corporate Governance", American Journal of Comparative Law, volumen LIX-1, pp. 75-110.

Di Cataldo, Vincenzo (2011): "Società a responsabilità limitata e autonomía statutaria. Un regalo poco utilizzato, e forse poco utile”, Rivista di Diritto Societario, volumen 3: pp. 556-569.

Duque Domínguez, Justino (1991): "Escritura, estatutos y límites a la libertad estatutaria en la fundación de sociedades anónimas”, en Alonso Ureba, Alfonso (coord.), Derecho de sociedades anónimas (en homenaje al profesor José Girón Tena), I: La fundación (Madrid, Civitas), pp. 15-110.

Embid Irujo, José Miguel (2003): "Consideraciones generales sobre la 'Sociedad Limitada Nueva Empresa”, en: Boquera Matarredona, J. (dir.), La sociedad limitada nueva empresa. Comentario a los artículos 130 a 144 y a las Disposiciones adicionales $8^{a}$ a $13^{a}$ de la LSRL (Cizur Menor, Aranzadi), pp. 19-34.

Embid Irujo, José Miguel (2006): "Derecho, mercado y responsabilidad social corporativa", Papeles de Economía Española, volumen 108: pp. 63-72.

Embid Irujo, José Miguel (2009): “El presente incierto del Derecho de sociedades”, Revista de Derecho Mercantil, volumen 272: pp. 453-482.

Embid Irujo, José Miguel (2011): “Cuestiones de tipología societaria en la Ley de sociedades de capital”, en: Piloñeta Alonso, Luis Manuel; Iribarren Blanco, Miguel (eds.), Estudios de Derecho Mercantil en homenaje al profesor José María Muñoz Planas (Cizur Menor, Thomson Reuters-Civitas), pp. 169-183.

European Commission (2011): "Green paper The EU Corporate Governance Framework", Rivista delle Società, volumen 56: pp. 1200-1221.

Fernández Armesto, J. (2012): "El arbitraje societario en la última reforma”, El Notario del Siglo XXI, volumen 43: pp. 122-125.

Fernández de la Gándara, Luis (2010): Derecho de sociedades (Valencia, Tirant lo Blanch), tomo I, 1295 pp. 
Girón Tena, José (1976): Derecho de sociedades, I: Teoría general. Sociedades colectivas y comanditarias (Madrid, edición del autor), $728 \mathrm{pp}$.

Gispert Pastor, María Teresa, "Afectación del patrimonio y de pequeños empresarios a los riesgos del negocio", Revista de Derecho Mercantil, volumen 164: pp. 283-298.

González Castilla, F.; Rodríguez Artigas, F.; Farrando, I. (dir.), Las reformas de la Ley de sociedades de capital (Cizur Menor, 2012).

Grundmann, Stefan (2011): Europäisches Gesellschaftsrecht (Heidelberg, C.F. Müller) 557 pp.

Guyon, Yves (2002): "Les sociétés. Aménagements statutaires et conventions entre associés”, en: Ghestin, Jacques (dir.), Traité des contrats (LGDJ, París, 5ª ed.), 462 pp.

Hierro Aníbarro, Santiago (dir.), Simplificar el Derecho de sociedades (Madrid, Marcial Pons), 608 pp.

Норт, Klaus J. (2011): "Vergleichende Corporate Governance. Forschung und internationale Regulierung", Zeitschrift für das gesamte Handels- und Wirtschaftsrecht, volumen 175-4, pp. 444-527.

Muñoz Paredes, María Luisa (2011): "Los ultra vires de la Ley de sociedades de capital", en: Piloñeta Alonso, Luis Manuel; Iribarren Blanco, Miguel (eds.), Estudios de Derecho Mercantil en homenaje al profesor José Maria Muñoz Planas (Cizur Menor, Thomson Reuters-Civitas), pp. 549-572.

Noval Pato, Jorge (2012): Los pactos omnilaterales: su oponibilidad a la sociedad. Diferencias y similitudes con los estatutos y los pactos parasociales (Cizur Menor, Aranzadi) 164 pp.

Quijano GonzÁlez, Jesús (2011): "El proceso de elaboración de la Ley de sociedades de capital”, en: Rojo Fernández-Río, Ángel; Beltrán Sánchez, Emilio (dir.), Comentario a la Ley de sociedades de capital (Cizur Menor, Aranzadi), tomo I, pp. 159-175.

Sánchez Calero, Fernando; Sánchez-Calero Guilarte, Juan (2011): Instituciones de Derecho mercantil (Cizur Menor, Aranzadi, 34ª ed.), tomo I, 878 pp.

Vaquerizo Alonso, Alberto (2011): “Artículo 1" (2011), en: Rojo Fernández-Río, Ángel; Beltrán SÁnchez, Emilio (dir.), Comentario a la Ley de sociedades de capital (Cizur Menor, Aranzadi), tomo I, pp. 182-192.

Yanes Yanes, Pedro (2011): "Los pactos parasociales no comunicados", en: Piloñeta Alonso, Luis Manuel; Iribarren Blanco, Miguel (eds.), Estudios de Derecho Mercantil en homenaje al profesor José María Muñoz Planas (Cizur Menor, Thomson Reuters-Civitas), pp. 909-928.

\section{RESOLUCIONES CITADAS DE LA DIRECCIÓN GENERAL DE LOS REGISTROS Y DEL NOTARIADO}

Resolución de 10 de octubre de 2011.

Resolución de 29 de octubre de 2011.

Resolución de 16 de noviembre de 2011.

Resolución de 26 de enero de 2012. 
